\title{
Capacitive behavior of highly-oxidized graphite
}

\author{
Mateusz Ciszewski*, Andrzej Mianowski \\ Department of Inorganic, Analytical Chemistry and Electrochemistry, Faculty of Chemistry, \\ Silesian University of Technology, Krzywoustego 6, 44-100 Gliwice, Poland
}

\begin{abstract}
Capacitive behavior of a highly-oxidized graphite is presented in this paper. The graphite oxide was synthesized using an oxidizing mixture of potassium chlorate and concentrated fuming nitric acid. As-oxidized graphite was quantitatively and qualitatively analyzed with respect to the oxygen content and the species of oxygen-containing groups. Electrochemical measurements were performed in a two-electrode symmetric cell using $\mathrm{KOH}$ electrolyte.

It was shown that prolonged oxidation causes an increase in the oxygen content while the interlayer distance remains constant. Specific capacitance increased with oxygen content in the electrode as a result of pseudo-capacitive effects, from 0.47 to $0.54 \mathrm{~F} / \mathrm{g}$ for a scan rate of $20 \mathrm{mV} / \mathrm{s}$ and 0.67 to $1.15 \mathrm{~F} / \mathrm{g}$ for a scan rate of $5 \mathrm{mV} / \mathrm{s}$. Better cyclability was observed for the electrode with a higher oxygen amount.
\end{abstract}

Keywords: graphite oxide; oxidation; supercapacitors

(C) Wroclaw University of Technology.

\section{Introduction}

Graphite oxide (GO), disordered material prepared by graphite treatment with a strong oxidizer in nonaqueous conditions, has been known since the 19th century. It was first synthesized in 1859 by Brodie [1] who treated graphite powder with a mixture of potassium chlorate and fuming nitric acid. In that method graphite was oxidized several times with fresh portion of acid and oxidizer but quick evaporation of nitric acid was very troublesome. Graphite oxidation was improved about forty years later by Staudenmaier [2]. He used higher excess of oxidizer with respect to graphite adding concentrated sulfuric acid that allowed longer oxidation in a single step. Hummers [3] proposed the simplest and less hazardous technique by mixing graphite with potassium permanganate in concentrated sulfuric acid, so several hours instead of days were needed for oxidation. Although all of these techniques result in obtaining highly-oxidized graphite, the advantages of the Brodie method in comparison to the latter ones are graphite oxide purity (no sulfate ions) and high oxygen content, however, the drawbacks are time needed to obtain well-

*E-mail: mateusz.ciszewski@polsl.pl oxidized graphite (several hours in the Hummers' method, $100-300 \mathrm{~h}$ in the Staudenmaier's and above $150 \mathrm{~h}$ using Brodie method) and difficulties with handling concentrated fuming nitric acid. It was found [4] that graphite oxide prepared by Brodie method is very stable, less contaminated and the brightest; moreover it has the smallest interlayer distance in comparison to graphite oxide obtained by other methods. It should be depicted that single oxidation using Brodie method takes about two days but careful drying is required because the oxidation is carried out in $100 \%$ nitric acid so water content should be as low as possible to avoid undesirable reactions. Drying in an oven is the fastest, however, due to possible desorption of epoxy groups drying in desiccator over phosphorus pentoxide was used. Because Brunauer-EmmettTeller (BET) surface area and interplanar spaces of graphite oxide increase with increasing oxygen content [5] the highly-oxidized graphite may be a potential matrix for active species in catalysis and energy storage devices. However, there are some difficulties in estimating the real specific surface area of graphite oxide by nitrogen adsorption because nitrogen molecules are not able to penetrate into the interlayer space [6]. The presence of oxygen functionalities has an advantage of an im- 
proved wettability but the drawback is the limited electron transfer, important in energy storage [7]. In spite of low conductivity, graphite oxide was considered in electrochemical devices [8, 9].

\section{Experimental}

\subsection{Materials and methods}

Graphite oxide was synthesized from synthetic graphite according to the modified Brodie method. Briefly, $10 \mathrm{~g}$ of graphite (Fisher Scientific, mesh $20 \mu \mathrm{m}$, humidity $0.26 \%$ ) was magnetically mixed with $60 \mathrm{~mL} 100 \%$ fuming $\mathrm{HNO}_{3}$ (Sigma Aldrich, p.a.) in an ice bath. Then $85 \mathrm{~g}$ of $\mathrm{KClO}_{3}$ (POCh, p.a.) was added during $5 \mathrm{~h}$. Next, the graphite oxide slurry was mixed at $\sim 55{ }^{\circ} \mathrm{C}$ for $6 \mathrm{~h}$. Thick paste was diluted with $2 \mathrm{~L}$ deionized water (Millipore, $0.0067 \mathrm{~S} / \mathrm{m}$ ). After sedimentation the solution was decanted while the product was vacuumfiltrated using a filter paper with medium pores (Munktel, 389), washed several times with deionized water and dried in a desiccator with $\mathrm{P}_{2} \mathrm{O}_{5}$. The dry product was used as a substrate for the next oxidation step. Graphite oxides obtained after the first (GO 1), third (GO 3) and sixth (GO 6) oxidation steps were analyzed.

\subsection{Characterization}

Products were characterized with powder X-ray diffraction (XRD, Seifert 3003) with a step size of $0.02^{\circ}$ and $\mathrm{Cu} \mathrm{K} \alpha$ radiation to evaluate the interlayer distance $\left(\mathrm{d}_{002}\right)$, crystallite height $\left(\mathrm{L}_{c}\right)$ and in-plane crystallite size $\left(\mathrm{L}_{a}\right)$. The IR-spectra were measured on a Nicolet 6700 FT-IR spectrophotometer using Attenuated Total Reflectance (ATR method). It enabled qualitative analysis of oxygen-containing groups. The presence and atomic percent of the oxygen-containing groups were confirmed by X-ray photoelectron spectroscopy (XPS, ESCALAB-210, VG Scientific).

\subsection{Electrochemical measurement}

Electrochemical experiments were carried out using two-electrode system. The working electrode materials composed of $90 \mathrm{wt} . \%$ of graphite oxide and $10 \mathrm{wt} . \%$ polytetrafluoroethylene (PTFE, Sigma Aldrich, $35 \mu \mathrm{m}$ ) were pasted on electrochemical nickel current collectors to form films containing $0.037 \mathrm{~g}$ of active material per electrode. The accurate weight of the electrodes was measured with a high-precision balance (Metler Toledo AT 261 DeltaRange). A polypropylene separator (Fipro 25, $0.35 \mathrm{~mm}$ thickness) soaked with $6 \mathrm{M} \mathrm{KOH}$ aqueous electrolyte was used in all measurements. The electrodes, current collectors and separator were pressed by four screws in poly(methyl methacrylate) casing. Cyclic voltammetry (CV) and electrochemical impedance spectroscopy (EIS) measurements were performed with an Autolab PGSTAT 30 workstation. EIS plots were tested in the frequency range of $100 \mathrm{kHz}$ to $100 \mathrm{mHz}$ with the amplitude of sinusoidal voltage signal equal to $10 \mathrm{mV}$ in the potential range of 0 to $1 \mathrm{~V}$ and step potential of $0.5 \mathrm{~V}$.

\section{Results and discussion}

Graphite oxide is a well-known graphitebased composite possessing turbostratically aligned graphene layers modified with the oxygen-containing species. Numerous GO models containing various oxygen species have been proposed [10, 11]. These intercalated groups are responsible for breaking of the van der Waals bonding that holds the layers together and changing carbon atoms hybridization from $\mathrm{sp}^{2}$ to $\mathrm{sp}^{3}$ as a result of $\pi-\pi$ bond breaking. The most visible effect of oxidation is color change from grey/graphitic to brown and even light yellow after a prolonged oxidizer treatment. Matuyama reported [12] that graphite treatment with $2: 1$ sulfuric to nitric acid resulted in blue color while addition of potassium chlorate changed the color to brown. Using different oxidation techniques various colors can be obtained. Structural change during graphite oxidation was studied by XRD presented in Fig. 1.

The typical sharp and strong graphitic signal located at $2 \theta=26^{\circ}$ is attributed to the highlyordered structure of graphite with high crystallites size. This peak shifts to about $12^{\circ}$ for graphite oxide due to the increase in the interlayer distance 
to $0.7 \mathrm{~nm}$, caused by intercalation of the oxygencontaining groups. The oxygen functional groups are responsible for the change of carbon atoms hybridization from $\mathrm{sp}^{2}$ to $\mathrm{sp}^{3}$ [13].

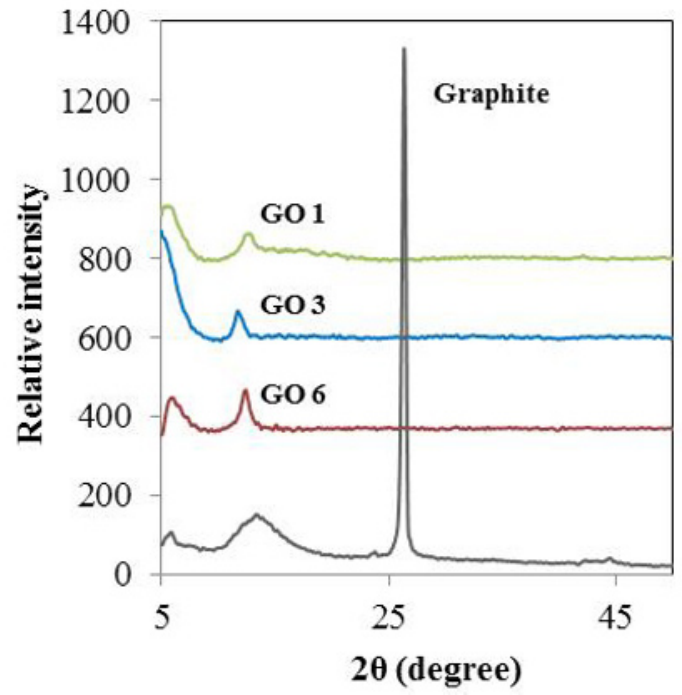

Fig. 1. XRD patterns of the first (GO 1), third (GO 3) and sixth (GO 6) oxidation step.

Table 1 presents the interlayer distance calculated after each oxidation step. Practically, there is a very little change in d-spacing, however, an increase in the oxygen content is still observed. Some discrepancies may result from water adsorbed in the interlayer space despite the prolonged drying. Graphite oxide hydration is a common problem that significantly increases the interlayer distance, oxygen content and changes the material properties, however, complete removal of water is practically impossible [14]. Even washing graphite oxide with water may cause significant chemical transformations resulting in various structures and properties [15], which can be overcome by quenching it in nonaqueous organic solvents.

Crystallites sizes were calculated using Scherrer equation. Severe reaction conditions resulted in crystallites height diminishing from $24 \mathrm{~nm}$ for a synthetic graphite to $\sim 6 \mathrm{~nm}$ for graphite oxide after the first oxidation, however, after the next oxidation steps, $\mathrm{L}_{c}$ value increased slightly to ca. $10 \mathrm{~nm}$. Probably it was caused by sticking of graphene layers during the prolonged oxidation. This trend was
Table 1. Comparison of the interlayer spacings and crystallite sizes for graphite and graphite oxides.

\begin{tabular}{|c|c|c|c|c|}
\hline & $\mathrm{L}_{c}[\mathrm{~nm}]$ & $\mathrm{L}_{a}[\mathrm{~nm}]$ & $002[\mathrm{~nm}]$ & $\mathrm{n}$ \\
\hline Graphite & 23.55 & 35 & 0.34 & 70 \\
\hline GO 1 & 6.05 & 22.6 & 0.7 & 9.6 \\
\hline GO 2 & 8.59 & 23.85 & 0.7 & 13.2 \\
\hline GO 3 & 8.67 & 15.77 & 0.75 & 12.6 \\
\hline GO 4 & 8.89 & 17.7 & 0.7 & 13.7 \\
\hline GO 5 & 10.47 & 23.36 & 0.73 & 15.3 \\
\hline GO 6 & 10.19 & 22.66 & 0.72 & 15.1 \\
\hline
\end{tabular}

not observed for the in-plane crystallites size that varied randomly. The theoretical number of layers (n) for graphite and graphite oxides was estimated based on $\mathrm{L}_{c} / \mathrm{d}_{002}+1$.

The qualitative analysis of the oxygencontaining groups was performed by FT-IR ATR.

Fig. 2 presents infrared spectra obtained for graphite oxide after single, triple and sixfold oxidation.

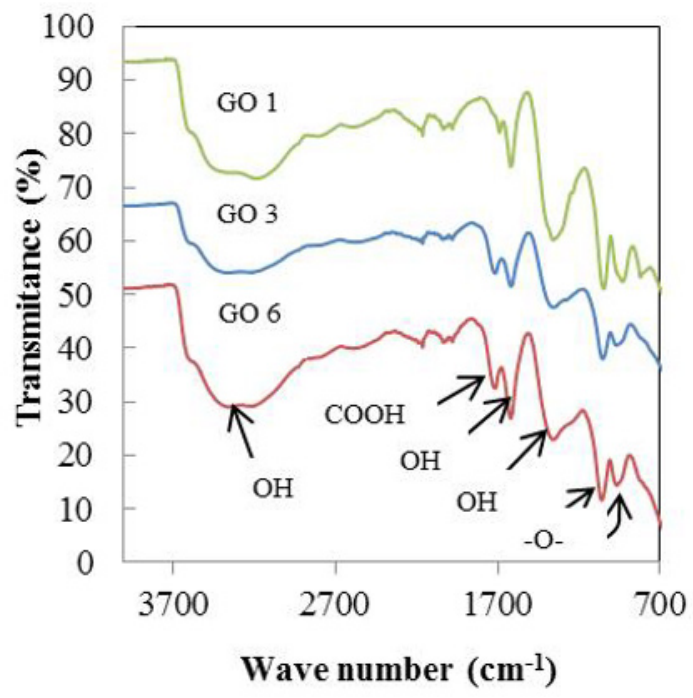

Fig. 2. FT-IR ATR spectra obtained for graphite oxides after various oxidation steps.

In all spectra the broad signal located at 3700 to $2800 \mathrm{~cm}^{-1}$, attributed to the stretching vibration in hydroxyl groups and water, can be ob- 
served. The signal at 1710 to $1705 \mathrm{~cm}^{-1}$ belongs to the carboxylic groups, at $1620 \mathrm{~cm}^{-1}$ to $\mathrm{OH}$ groups, $1350 \mathrm{~cm}^{-1}$ is due to deformation vibration in $\mathrm{C}-\mathrm{OH}, 1040$ to $1023 \mathrm{~cm}^{-1}$ represents $\mathrm{C}-\mathrm{O}$ groups, sometimes designated to $\mathrm{C}-\mathrm{C}$, and finally the peak around $950 \mathrm{~cm}^{-1}$ comes from epoxy groups. Pumera et al. [16] suggested that the large peak at $1600 \mathrm{~cm}^{-1}$ corresponded to the unoxidized $\mathrm{sp}^{2}$ regions but in fact the signal slightly above $1600 \mathrm{~cm}^{-1}$ was more often attributed to $\mathrm{OH}$ groups while the signal around $1580 \mathrm{~cm}^{-1}$, very common in Hummers graphite oxide, might result from $\mathrm{sp}^{2}$ domains. It was also shown that the signals location remained unchanged during oxidation only some differences in signals intensity were observed.

These results were confirmed by XPS analysis. Fig. 3 presents $\mathrm{C} 1 \mathrm{~s}$ spectra for GO 1, GO 3 and GO 6 that were deconvoluted into five separate peaks representing $\mathrm{C}=\mathrm{C} \mathrm{sp}{ }^{2}, \mathrm{C}-\mathrm{C} \mathrm{sp}{ }^{3}$, $\mathrm{C}-\mathrm{O} / \mathrm{C}-\mathrm{OH}, \mathrm{C}=\mathrm{O}$, and $\mathrm{COOH}$.

Five different peaks centered at 284.6, 285.8, 286.6, 287.9, and $288.9 \mathrm{eV}$, corresponding to $\mathrm{C}=\mathrm{C}$ $\mathrm{sp}^{2}, \mathrm{C}-\mathrm{C} \mathrm{sp}^{3}, \mathrm{C}-\mathrm{O} / \mathrm{C}-\mathrm{OH}, \mathrm{C}=\mathrm{O}$, and $\mathrm{COOH}$ groups, respectively, are observed [17]. With the increase in reaction time the intensities of $\mathrm{C}=\mathrm{O}$ and $\mathrm{C}-\mathrm{O} / \mathrm{C}-\mathrm{OH}$ increase. Interestingly, the amount of $\mathrm{COOH}$ groups decreased after the first oxidation with the increase of other oxygen species. So, in the highly-oxidized graphite the oxygen-containing groups are mostly composed of carbonyl and hydroxyl/epoxy groups located between the graphene layers.

Quantitative analysis of the oxygen species obtained using XPS are presented in Tables 2 and 3 that summarize the atomic content of the particular carbon-carbon and carbon-oxygen groups and the area under the curves, respectively.

A decrease in carboxylic groups content from about 13 at. $\%$ after single oxidation to about 4 at.\% as well as some increase in hydroxyl/epoxy groups are confirmed. An increase in the amount of the $\mathrm{sp}^{2}$ hybridized carbon atoms and simultaneously slight decrease in $\mathrm{sp}^{3}$ domains can be observed. This may result from the slight increase in crystallites height during oxidation presented in Table 1. Probably some restacking of graphite oxide has
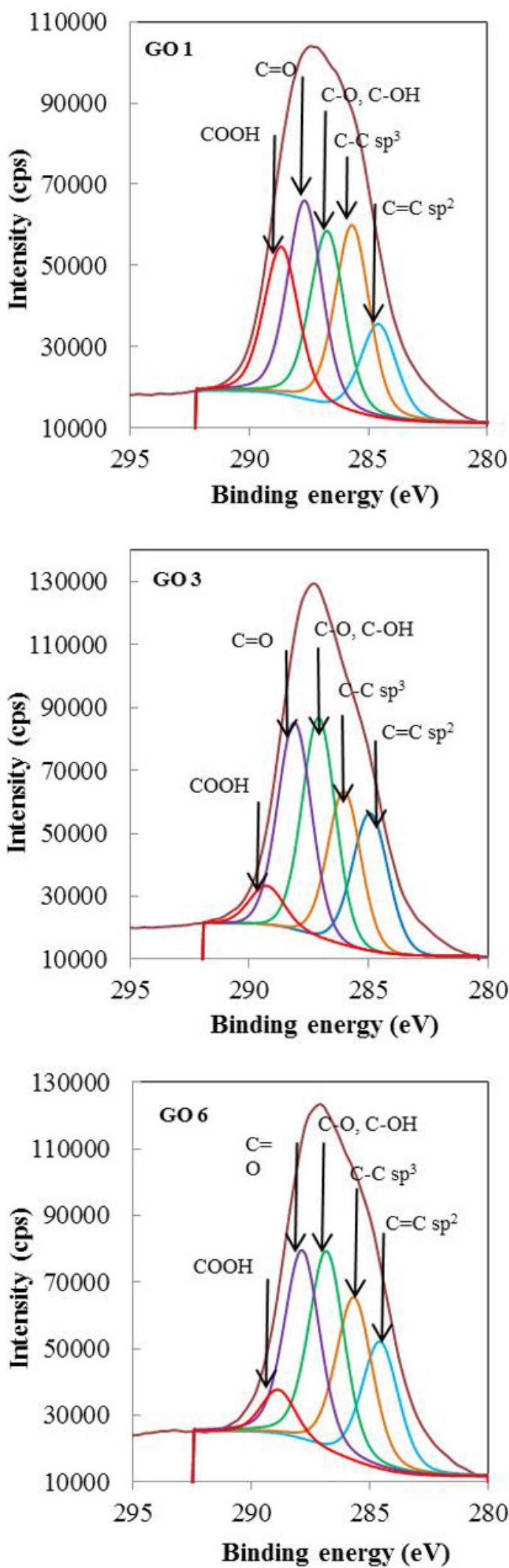

Fig. 3. C 1s spectra obtained for GO 1, GO 3, and GO 6. 
Table 2. Atomic percent of carbon-carbon and carbon-oxygen bonding.

\begin{tabular}{cccc}
\hline Group & GO 1 & GO 3 & GO 6 \\
\hline C 1s & & & \\
\hline \hline $\mathrm{C}-\mathrm{C} \mathrm{sp}{ }^{2}$ & 8.67 & 12.39 & 11.82 \\
$\mathrm{C}-\mathrm{C} \mathrm{sp}{ }^{3}$ & 16.29 & 12.85 & 15.08 \\
$\mathrm{C}-\mathrm{O} / \mathrm{C}-\mathrm{OH}$ & 15.22 & 18.35 & 17.87 \\
$\mathrm{C}=\mathrm{O}$ & 17.3 & 17.67 & 17.02 \\
$\mathrm{O}=\mathrm{C}-\mathrm{O}$ & 12.83 & 3.31 & 3.89 \\
\hline $\mathbf{O ~ 1 s}$ & & & \\
\hline \hline $\mathrm{C}-\mathrm{OH}$ & 9.11 & 14.22 & 13.15 \\
$\mathrm{O}=\mathrm{C}-\mathrm{O}$ & 10.19 & 7.37 & 7.54 \\
$\mathrm{C}=\mathrm{O}$ & 5.2 & 8.09 & 6.55 \\
oxides & 1.89 & 0 & 1.87 \\
\hline
\end{tabular}

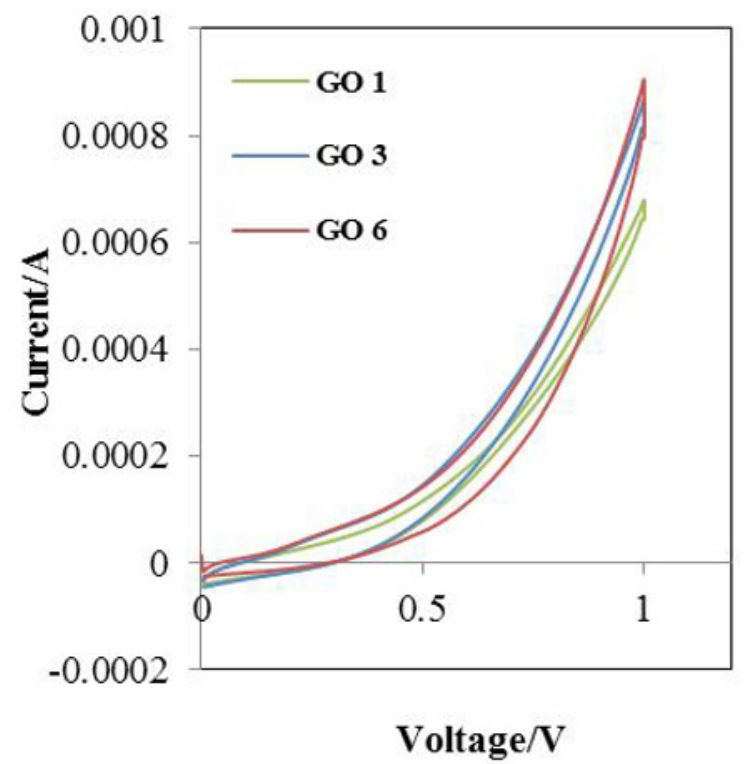

Table 3. Peaks areas of the oxygen-containing groups.

\begin{tabular}{cccc}
\hline & \multicolumn{3}{c}{ Lines integral intensities } \\
\hline \hline Group & GO 1 & GO 3 & GO 6 \\
C-O/C-OH & 88.212 & 123.390 & 127.158 \\
$\mathrm{C}=\mathrm{O}$ & 100.238 & 118.836 & 121.149 \\
$\mathrm{O}=\mathrm{C}-\mathrm{O}$ & 74.324 & 22.244 & 27.664 \\
\hline
\end{tabular}

occurred. Fig. 4 and 5 present cyclic voltammograms of GO 1, GO 3, and GO 6 after 10 and 100 cycles respectively, in the potential window of 0 to $1 \mathrm{~V}$ with a scan rate of $20 \mathrm{mV} / \mathrm{s}$. After first few cycles the higher values of current and specific capacity are obtained namely $0.47 \mathrm{~F} / \mathrm{g}$ for GO 1 , $0.58 \mathrm{~F} / \mathrm{g}$ for $\mathrm{GO} 3$, and $0.54 \mathrm{~F} / \mathrm{g}$ for GO 6 but the shape of the curves is very narrow. After $100 \mathrm{cy}$ cles the $\mathrm{CV}$ curves are more rectangular and more close to an ideal supercapacitor behavior, however, the capacity is much lower, i.e. $0.057,0.048$, and $0.14 \mathrm{~F} / \mathrm{g}$, respectively.

The CV curve of GO 6 is more box-like than those obtained for GO 1 and GO 3, which is probably caused by the abundant oxygencontaining groups that may provide additional pseudo-capacitance and better wettability [18]. Presumably longer oxidation caused more homogenous distribution of active sites, therefore, the specific capacity drop in GO 6 is not as big as in

Fig. 4. CV curves recorded after 10 cycles $(20 \mathrm{mV} / \mathrm{s})$ for GO 1, GO 3, and GO 6.

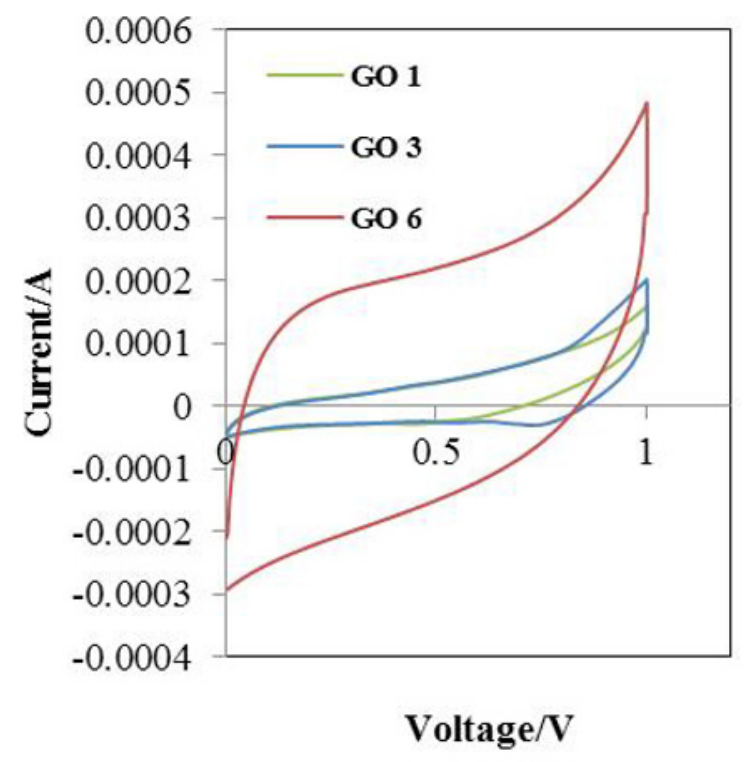

Fig. 5. CV curves obtained at a scan rate of $20 \mathrm{mV} / \mathrm{s}$ after 100 cycles for three oxidized graphite samples.

GO 1 and GO 3. Fig. 6 compares CV curves of GO 6 recorded after 60, 70, 80, 90 and 100 cycles. This material presents a relatively good cycling ability and the lowest specific capacity drop in comparison to the GO 1 and GO 3. This indicates 
that the oxygen-containing groups are not utilized in a few first cycles but are gradually consumed in reactions with electrolyte. This enhances positive pseudo-capacitance for a longer working time.

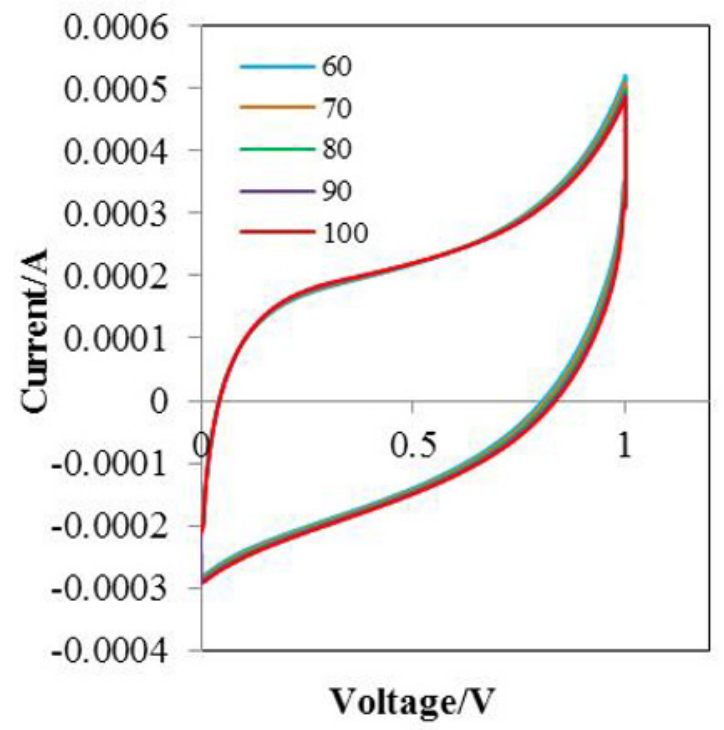

Fig. 6. CV curves recorded for GO 6 after 60, 70, 80, 90 and 100 cycles.

Additionally, all of the samples were cycled in the same potential range with a scan rate of $5 \mathrm{mV} / \mathrm{s}$. Similarly to the higher scan rate the curves broadening in time was observed. In the tenth cycle very narrow $\mathrm{CV}$ profiles were obtained and the specific capacity was $0.67 \mathrm{~F} / \mathrm{g}, 1.12 \mathrm{~F} / \mathrm{g}$ and $1.15 \mathrm{~F} / \mathrm{g}$ for GO 1, GO 3, and GO 6, respectively. These curves broadened during the cycling with simultaneous specific capacity decrease to $0.42,0.61$, and $0.75 \mathrm{~F} / \mathrm{g}$, respectively.

Fig. 7 presents $\mathrm{CV}$ curves after 30 cycles with a scan rate of $5 \mathrm{mV} / \mathrm{s}$. Once again some activation of electrode material in time is observed, which is the most striking in GO 6. Probably this can be attributed to rapid utilization of oxygen-containing groups at the edge of layers. During working, more interlayer space is penetrated by electrolyte. GO 1 has the highest amount of carboxylic groups and the narrowest initial CV curve, while GO 3 and GO 6 have relatively lower amount of functional groups located at the edge and their initial $\mathrm{CV}$ curves are broader. As the electrolyte is $\mathrm{KOH}$ it is probable that the first charging processes are needed to build double layers inside the electrodes like in activated porous carbons [19].

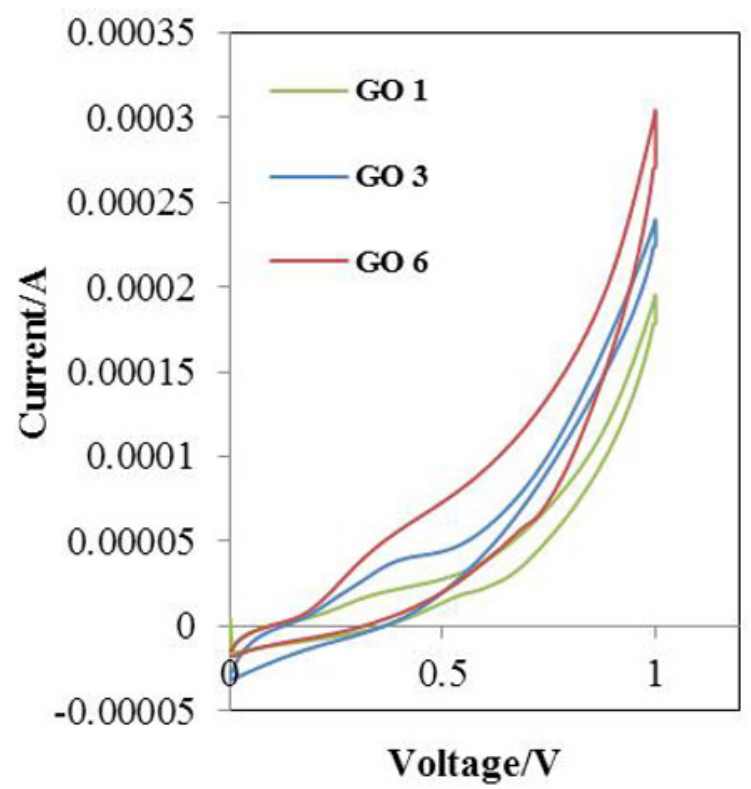

Fig. 7. The $\mathrm{CV}$ profiles of graphite oxides at a scan rate of $5 \mathrm{mV} / \mathrm{s}$, after 30 cycles.

These results are similar to those obtained in literature [20] for graphite oxide. Typically higher values are obtained for a three-electrode test cell than for two-electrode system [21], but the latter is more relevant for capacity measurements.

The electrochemical impedance spectroscopy plots obtained at 0 and $1 \mathrm{~V}$ are shown in Fig. 8 and Fig. 9, respectively. EIS can be used to understand the resistive components involved with electrochemical systems, what is very important for supercapacitors characterization. EIS plots present quasi-reversible behavior of graphite oxide, most evident for GO 6, with two distinguished regions including the semicircle corresponding to the faradaic charge transfer resistance [22] and the straight line in the low-frequency region indicating a pure capacitive behavior and representing the ion diffusion in the electrode structure [23]. This phenomenon is practically negligible in GO 1 and GO 3, where less steep curves have been recorded and, consequently, higher resistances of ions diffusion are obtained. A more steep curve in the 
low-frequency region is attributed to better Warburg diffusion, that is responsible for more effective mass transfer from the electrolyte to the electrode interface.

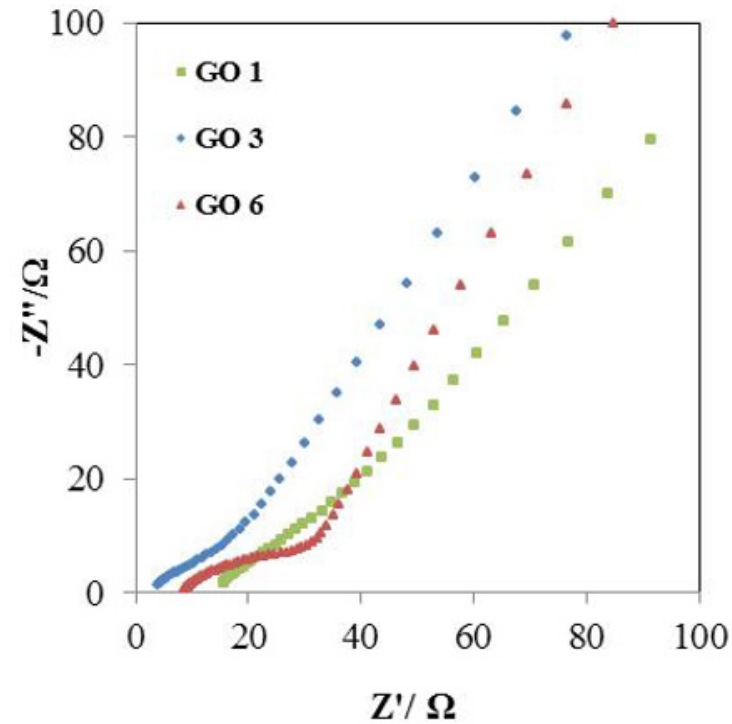

Fig. 8. Nyquist plots for capacitors based on GO 1, GO 3, and GO 6 recorded at $0 \mathrm{~V}$.

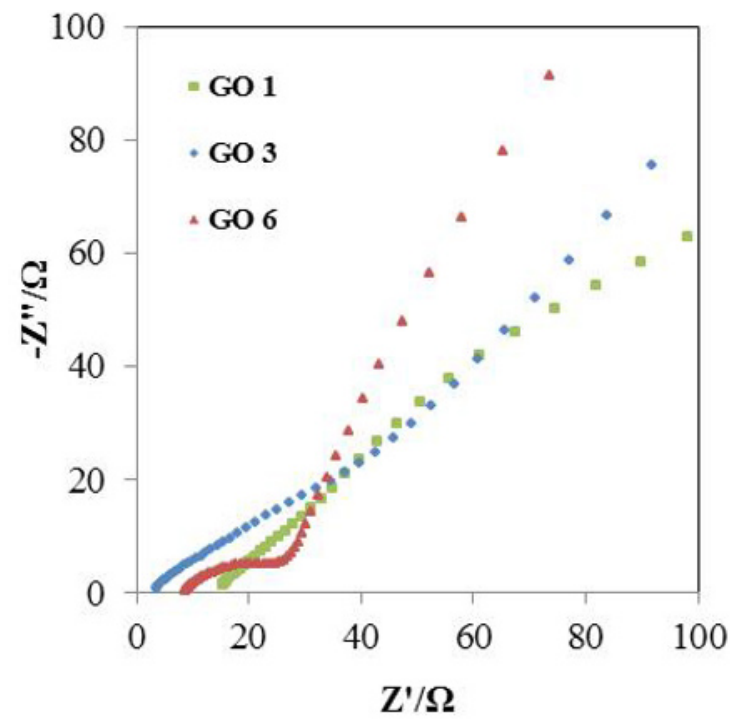

Fig. 9. Nyquist plots for capacitors based on GO 1, GO 3, and GO 6 recorded at $1 \mathrm{~V}$.

We suppose that the better characteristics of GO 6 results from the better penetration of the interlayer spaces by the electrolyte caused by more ordered structure of GO 6 in comparison to GO 1 and GO 3 (higher crystallites height) and improved wettability due to the highest oxygen amount. Although the difference in oxygen amount is not big it was previously mentioned that the structure and properties of graphite oxide may strongly depend on the purification method.

\section{Conclusions}

In this work, we have reported that highlyoxidized graphite prepared by multiple oxidation was composed mainly of hydroxyl/epoxy and carbonyl groups. The interlayer distance did not change significantly during oxidation and the oxygen content varied slightly from 26 to 30 at.\%. A gradual decrease in carboxylic groups was observed during oxidation. Additionally, the increase in $\mathrm{C}=\mathrm{C} \mathrm{sp}{ }^{2}$ domains was recorded, what is probably the result of graphite oxide restacking while the slight increase in crystallite height could be caused by sticking of unoxidized graphene layers. The materials were electrochemically tested as electrodes in supercapacitors using a two-electrode test cell. Initially narrow $\mathrm{CV}$ profiles were observed in all samples, which indicated some activation of the electrode material. During longer cycling more rectangular curves were obtained. For GO 6 the shape of the curve was the most box-like, however, still the peak in the high voltage was observed. The presence of oxygen-containing groups is beneficial to the application of graphite oxide-based supercapacitors. Nyquist plots showed differences in electrode material resistances. In the highly-oxidized GO 6 typical quasi-reversible plot was observed with the semicircle corresponding to faradaic reaction and the slope of about 45 degree in the low frequency region. Although the difference in GO 1 and GO 6 behavior seems to be the consequence of the oxygen content, it is still unclear why GO 3 differs so strongly from GO 6. Probably several effects interfere here. The GO 6 has the highest oxygen content, i.e. aqueous electrolyte can easily penetrate it. Relatively small amount of carboxylic groups located at the edge of graphene layers make the interlayer space more easily accessible, while the highest crystallite height indicates 
its ordered structure with probably well-developed pores. Some discrepancies may result from the differences in purification and compression stress of the samples, too.

\section{References}

[1] Brodie B.C., Philos. T. R. Soc. A, 149 (1859), 249.

[2] Staudenmaier L., Ber. Dtsch. Chem. Ges., 31 (1898), 1481.

[3] Hummers W.S., Offeman R.E., J. Am. Chem. Soc., 80 (1958), 1339.

[4] Jeong H.-K., Lee Y.P., Lahaye R.J.W.E., Park M.-H., AN K.H., KIM I.J., YANG C.-W., PARK C.Y., RuOfF R.S., LEE Y.H., J. Am. Chem. Soc., 130 (2008), 1362.

[5] Wang H., Hu Y.H., Ind. Eng. Chem. Res., 50 (2011), 6132.

[6] Seredych M., Bandosz T.J., J. Phys. Chem. C, 111 (2007), 15596.

[7] Ambrosi A., Bonanni A., Sofer Z., Cross J.S., Pumera M., Chem.-Eur. J., 17 (2011), 10763.

[8] Hamwi A., Marchand V., J. Phys. Chem. Solids, 57 (1996), 867.

[9] Ra E.J., Tran M.-H., YANG S., KIM T.-H., YANG C.-S., Chung Y.-J., LeE Y.-K., KIM I.-J., JeOnG H.-K., Curr. Appl. Phys., 14 (2014), 82.

[10] Szabo T., Berkesi O., Forgo P., Josepovits K., SANAKIS Y., PETRIDIS D., DeKANY I., Chem. Mater, 18 (2006), 274.

[11] Lerf A., He H., Forster M., Klinowski J., J. Phys. Chem. B, 102 (1998), 4477.

[12] Matuyama E., J. Phys. Chem., 58 (1954), 215.
[13] MCAllister M.J., Li J.-L., AdAmson D.H., SChNiepr H.C., Abdala A.A., LiU J., HerreraAlonso M., Milius D.L., CAR R., Prud'Homme R.K., AKSAY I.A., Chem. Mater., 19 (2007), 4396.

[14] Talyzin A.V., Szabo T., Dekany I., LangenHORST F., SOKOlOV P.S., SOlOZHENKo V.L., J. Phys. Chem. C, 113 (2009), 11279.

[15] Dimiev A., Kosynkin D.V., Alemany L.B., CHAguine P., Tour J.M., J. Am. Chem. Soc., 134 (2012), 2815.

[16] Chua C.K., Sofer Z., Pumera M., Chem.-Eur. J., 18 (2012), 13453.

[17] FAN Z.-J., KAI W., YAN J., WEI T., ZHI L.-J., FENG J., Ren Y., Song L.-P., We F., ACS Nano, 5 (2011), 191.

[18] Xu B., Yue S., Sui Z., Zhang X., Hou S., CaO G., YANG Y., Energ. Environ. Sci., 4 (2011), 2826.

[19] Kim I.-J., Yang S., Jeon M.-J., Moon S.-I., KIM H.-S., LeE Y.-P., AN K.-H., LEE Y.-H., J. Power Sources, 173 (2007), 621.

[20] Buglione L., Chng E.L.K., Ambrosi A., Sofer Z., Pumera M., Electrochem. Commun., 14 (2012), 5.

[21] Frackowiak E., Khomenko V., Jurewicz K., Lota K., Beguin F., J. Power Sources, 153 (2006), 413.

[22] Chen Y., Zhang X., Zhang D., Yu P., Ma Y., Carbon, 49 (2011), 573.

[23] Portet C., Taberna P.L., Simon P., LabertyRobert C., Electrochim. Acta, 49 (2004), 905.

Received 2013-01-30 Accepted 2014-04-17 